\title{
Étude microtopographique des fortifications de terre de Haute-Normandie
}

\section{Anne-Marie Flambard-Héricher}

\section{QpenEdition \\ Journals}

Édition électronique

URL : http://journals.openedition.org/adlfi/8020

ISSN : 2114-0502

Éditeur

Ministère de la culture

Référence électronique

Anne-Marie Flambard-Héricher, «Étude microtopographique des fortifications de terre de HauteNormandie », ADLFI. Archéologie de la France - Informations [En ligne], Haute-Normandie, mis en ligne le 01 mars 2005, consulté le 19 avril 2019. URL : http://journals.openedition.org/adlfi/8020

Ce document a été généré automatiquement le 19 avril 2019

(c) Ministère de la Culture et de la Communication, CNRS 


\title{
Étude microtopographique des fortifications de terre de Haute- Normandie
}

\author{
Anne-Marie Flambard-Héricher
}

Date de l'opération : 1982 - 2005 (PC)

1 En 1982, sous l'égide de Jean-Marie Pesez alors vice-président du Conseil scientifique de la recherche archéologique (CSRA), et de Michel de Boüard qui venait d'organiser le colloque de Caen consacré aux fortifications de terre, un groupe de chercheurs français, sensibilisé aux problèmes posés par ce type de fortifications se réunissait pour tenter de mettre en place une structure et définir une démarche susceptibles d'aider au recensement et à la sauvegarde de ces sites particulièrement menacés du fait des remembrements, des grands travaux de toute nature, et du perfectionnement des moyens mécaniques agricoles.

2 Ensemble, d'abord de manière informelle puis plus organisée, avec l'appui du ministère de la Culture et du CNRS, une fiche descriptive fut élaborée et des régions pilotes désignées. Mais l'expérience ne fut pas véritablement pérennisée, le travail de relevé, en particulier, demandant un très lourd investissement des participants.

3 Trente ans plus tard, les choses n'ont guère changé. Les fortifications de terre sont un peu mieux connues grâce aux recensements opérés régionalement pour la Carte archéologique, mais le travail reste souvent superficiel et les relevés topographiques qui constituaient l'essentiel de la base documentaire n'ont pas beaucoup progressé. L'objectif $\mathrm{du}$ groupe de travail qui s'est constitué à l'université de Rouen, au sein du GRHIS (EA 3831), avec l'appui du service régional de l'Archéologie de Haute-Normandie, sous la direction d'Anne-Marie Flambard-Héricher, est de pratiquer de façon systématique des relevés microtopographiques, de les décrire suivant la grille élaborée dès 1982 et de les interpréter à la lumière de cet examen approfondi, qui peut être croisé 
avec des observations de surface systématiques : notamment microreliefs, répartition des pierres taillées et mode de taille, répartition de la flore.

4 Les recherches ont porté sur huit sites fortifiés, connus ou inédits.

5 (Responsable du PCR : Anne-Marie Flambard Héricher)

\section{BAZINCOURT-SUR-EPTE (Eure)}

6 « Le Château-Saussart »

7 Le château domine le cours de l'Epte de $70 \mathrm{~m}$. Au sommet d'un coteau et à l'écart de toute agglomération, le site est composé de deux enceintes. La première dont la levée de terre, de $25 \mathrm{~m}$ de diamètre, en forme de fer à cheval est plus forte vers le plateau, au sud-ouest. Vers le nord-est, une interruption du fossé marque l'accès vers la basse-cour de $45 \mathrm{~m}$ de diamètre. L'entrée est placée à proximité de la jonction des deux enceintes, vers le nordouest.

8 La typologie, le contexte géographique et politique permettent de placer l'origine du site vers le milieu du XI ${ }^{\mathrm{e}}$. Cette petite fortification s'apparente à un relais entre les châteaux importants de Neufmarché-en-Lyons (Seine-Maritime) et Neaufles-Saint-Martin (Eure), situés à $8 \mathrm{~km}$ vers le nord et le sud. Ces deux places ont fait l'objet d'une mise en défense par Guillaume-le-Bâtard peu après le milieu du $\mathrm{XI}^{\mathrm{e}} \mathrm{s}$., pour garantir ce secteur frontalier contre le pouvoir capétien.

(Relevé et présentation sous la direction de Bruno Lepeuple).

\section{BUS-SAINT-RÉMY (Eure)}

face à l'île-de-France. Le site est composé de trois enceintes imbriquées les unes dans les autres. Une première, au nord-est, assise sur le rebord du plateau, est caractérisée par un fort talus décroissant qui domine de plus de $15 \mathrm{~m}$ le fond d'un fossé en forme de fer-àcheval. Au sud de cette première enceinte se développe une basse-cour, elle aussi située au niveau de la rupture de pente. Une arête rocheuse qui traverse nettement ces deux éléments, donne des indications sur le mode de construction de la fortification et les contraintes topographiques qui ont présidé, éventuellement au choix du site, sinon à la manière de l'aménager. À l'ouest, se trouve une troisième enceinte, essentiellement caractérisée par son fossé formant un arc qui isole l'enceinte principale et une partie de la basse-cour du plateau.

dans les débuts de la confrontation franco-normande vers le milieu du XI ${ }^{\mathrm{e}} \mathrm{s}$. avec l'installation d'une seigneurie par le duc Guillaume le Bâtard. Plusieurs ruines et bâtiments permettent ensuite de tracer les grands traits d'une occupation longue. D'abord une courtine est édifiée au sommet de l'enceinte principale, vient ensuite un important programme de construction avec une cave, un bâtiment aux fonctions résidentielles et un important mur de soutènement du côté de la vallée. Les caractéristiques architecturales de ces éléments et une étude des sources écrites permettent de situer cette deuxième phase de construction vers le début du XIII ${ }^{\mathrm{e}}$. Une terrasse saillante, greffée sur le mur de soutènement, vient clore les aménagements 
militaires du site démantelé en 1437. Au niveau de la basse-cour, plusieurs bâtiments témoignent de la fonction agricole du lieu, du XVI ${ }^{\mathrm{e}} \mathrm{s}$. au début du XXes., lorsque le site devient résidentiel et que l'espace du château médiéval est aménagé en parc.

Directement au pied du château, vers l'est, se développe un noyau de peuplement restreint et concentré. Limites parcellaires, dénivelés, chemins et hydrographie permettent de cerner l'emprise d'un îlot bâti de $60 \mathrm{~m}$ x $140 \mathrm{~m}$. Cette petite surface n'est pas incompatible avec le nombre de feux - 7, soit 35 personnes environ - recensés vers le milieu du XIII ${ }^{e}$ s. L'église paroissiale, placée sous le vocable de Saint-Martin, et certainement antérieure au château, est aujourd'hui disparue. Un petit cimetière, placé sur une terrasse entre la zone d'habitat et le château, indique l'emplacement de l'édifice. Les sources écrites citent, en 1259, une "église ", et une "église du château ». Cette mention est à rapprocher d'une dalle funéraire, illisible mais certainement médiévale, sortie de terre il y a environ 30 ans, dans le quart sud-est de la basse-cour et servant aujourd'hui de banc dans le parc du château.

(Relevé et présentation sous la direction de Bruno Lepeuple).

\section{CHÂTEAU-SUR-EPTE (Eure)}

«Le Bois de la Brétêche »

Le site du «Bois de la Bretêche" se trouve au contact direct de l'Epte, en contrebas et $800 \mathrm{~m}$ à l'est du village. Les reliefs de ce site sont ténus mais occupent une importante surface au sol. Un tertre de $25 \mathrm{~m}$ de diamètre à la base est accolé à la rivière, ceinturé par un premier fossé hémicirculaire, puis un second qui ne l'enserre que sur son flanc nordouest avant d'adopter un tracé rectiligne de $80 \mathrm{~m}$ qui rejoint le cours d'eau. Depuis le tertre et vers le bourg, une levée de terre de $110 \mathrm{~m}$ de longueur et large de $13 \mathrm{~m}$ atteint $0,75 \mathrm{~m}$ de hauteur.

La défense n'est pas la vocation principale du site. Autour du point fort qu'est le tertre, il faut plutôt restituer un bief et un talus-barrage limitant une retenue d'eau. Ce dernier relief peut également avoir une fonction de chaussée associée à un franchissement de la rivière. Le rapprochement du site avec le bourg de Château-sur-Epte est évident. Ce noyau de peuplement s'est formé dans le premier quart du XII ${ }^{e}$., au pied d'un château fondé à la fin du XI ${ }^{\mathrm{e}} \mathrm{s}$.

(Relevé et présentation sous la direction de Bruno Lepeuple).

\section{DANGU (Eure)}

19 «Le Bois de Dangu »

20 Le site occupe le sommet d'un coteau qui domine la vallée de l'Epte, $1 \mathrm{~km}$ au nord du village. La fortification est contenue dans une parcelle boisée entièrement cernée par des espaces cultivés et la route de Dangu à Neaufles-Saint-Martin qui la borde au sud-est. Le site se décompose en trois enceintes alignées, tangentes, et dont la puissance des défenses décroît progressivement. La première, au nord-ouest, présente une levée de terre en forme de fer-à-cheval, de $25 \mathrm{~m}$ de diamètre, plus forte vers le plateau, à l'ouest, et entièrement ceinturée d'un fossé. L'accès à la deuxième enceinte se fait vers le sud, celleci est complexe et présente de nombreux microreliefs. L'ensemble est grossièrement 
rectangulaire si l'on excepte une surépaisseur du talus vers l'ouest, celui-ci est interrompu au sud-est entre deux monticules qui marquent l'accès vers la troisième enceinte. L'espace contenu entre les deux entrées est légèrement surélevé par rapport au reste de l'enceinte. La troisième enceinte s'organise à l'intérieur d'un quart de cercle de $60 \mathrm{~m}$ de rayon; il est rejoint par deux levées de terre qui assurent la connexion avec les deux monticules qui marquent l'entrée de la deuxième enceinte. Ce talus présente deux interruptions vers le sud et le nord-est. Une mare creusée immédiatement à l'extérieur de l'enceinte draine les eaux issues des fossés du flanc ouest de la fortification et d'une zone marécageuse qui s'étend de ce côté. La nature du sol est assez particulière, sur l'ensemble du site, on observe de nombreux galets de petite taille. Les levées de terre sont en partie constituées par l'accumulation de ce matériau que l'on retrouve également en blocs agglomérés, notamment au sommet du rempart de terre de l'enceinte principale. Ce détail soulève la question d'une utilisation de ces blocs dans la constitution de la levée de terre et leur participation aux aménagements défensifs.

Les trois enceintes ne semblent pas contemporaines les unes des autres. Néanmoins, la proximité du site de Neaufles-Saint-Martin avec lequel il est en communication visuelle, et les similitudes, au niveau de l'enceinte principale, avec le Château-Saussart, plaident pour un ouvrage à vocation militaire remontant au milieu du XI ${ }^{e}$ s. Pour les deux autres enceintes, l'hypothèse d'une maison forte venue se greffer sur un site plus ancien est privilégiée.

22 (Fig. ${ }^{\circ} 1$ : Relevé de la fortification du « Bois de Dangu »)

(Relevé et présentation sous la direction de Bruno Lepeuple).

\section{FOURGES (Eure)}

Le site occupe le point culminant d'une ligne de crête qui sépare les vallées de l'Epte et de la Seine. Le plan est atypique. Il s'agit d'une butte de terre très peu élevée, moins de $2 \mathrm{~m}$ en moyenne, de forme approximativement carrée et qui n'est bordée par un fossé que sur son côté nord-ouest. Une portion rectiligne de talus part du tertre vers le sud-est, dans la pente d'un fort coteau qui domine la Seine. La forme carrée, inhabituelle pour une petite fortification de terre, permet de supposer l'existence d'un coffrage de bois destiné à retenir les terres. La partie excavée, aujourd'hui très restreinte, ne correspond pas, même 
si elle a été en grande partie comblée, au volume des matériaux accumulés. Le tertre peut avoir été constitué de terre prélevée tout autour du site en raclant la couche superficielle du terrain car la craie affleure en de nombreux endroits. Il faut également citer la proximité du sanctuaire gallo-romain de Bennecourt (Yvelines), qui a pu faire l'objet d'une récupération.

Aucune source ne nomme formellement ce site, cependant, il correspond bien à un épisode précis de la confrontation franco-normande. La chronique d'Orderic Vital évoque, en 1118 , le siège de Gasny par les troupes d'Henri I ${ }^{\text {er }}$ Beauclerc. Le chroniqueur précise que le roi d'Angleterre a fait édifier deux châteaux de siège qu'il nomme le « Malassis » et le «Gîte du lièvre » (trulla leporis). Seul le premier est identifié, il s'agit d'une motte associée à une basse-cour sur la rive droite de l'Epte. Le tertre que l'on voit à Bellevue peut correspondre au second château mentionné par Orderic Vital. Il se situe en face de Malassis, ce qui barre la vallée de l'Epte en aval de Gasny et permet une surveillance de la vallée de la Seine. Enfin, la toponymie n'est certainement pas innocente, la stratégie du lièvre est de reprendre des terriers existants ou des creux de terrain propices à fournir un abri. Cette appellation est en parfaite équation avec le site de Bellevue : un aménagement minimum sur un site naturellement favorable à la surveillance et éventuellement constitué de matériaux récupérés. En l'absence d'autres éléments, c'est l'année 1118 qui est retenue pour la datation de ce site.

(Relevé et présentation sous la direction de Bruno Lepeuple).

\section{LANDIN (Le) (Eure)} doivent permettre d'effectuer une cartographie des sites fortifiés de cette famille - principalement implantés à proximité du réseau hydrographique (le long de la Seine, de l'Eure et de la Risle) - et d'en dresser une typochronologie (donjons quadrangulaires, donjons annulaires (ou shell-keeps), éperons barrés, etc.). Au XII ${ }^{\mathrm{e}}$., cette " géographie castrale » est principalement limitée au nord et à l'ouest par les châteaux ducaux, au sudest par ceux des seigneurs de Tosny, ennemis héréditaires des Beaumont-Meulan.

« Motte du Landin »

Les investigations menées respectivement sur les sites de «La butte de l'Ecuyer » à Vatteville-la-Rue (Seine-Maritime) et de « La motte du Landin » (Eure), tous deux localisés au contact de la forêt de Brotonne sont à l'origine d'une vaste étude "géoarchéologique » élargie depuis janvier 2006 à l'ensemble des fortifications médiévales liées, en basse Seine, à la puissante famille des Beaumont-Meulan.

Les études historiques, relevés topographiques et observations archéologiques du bâti L'une des premières investigations entreprise concerne le vaste domaine agricole et seigneurial du Landin, situé à l'est de la forêt de Brotonne. Il fut acheté à l'abbaye de Jumièges en 1123 par Galeran de Meulan ou l'un de ses vassaux, et se situe au contact d'un imposant domaine forestier, d'un vaste territoire céréalier (le plateau du Roumois) et d'une cavée menant à la Seine, lieu de passage incontournable. Un manuscrit exceptionnel y atteste la construction d'une structure fortifiée (castellum), en 1123, un an avant le siège par Henri I ${ }^{\text {er }}$ Beauclerc du château des comtes de Meulan à Vatteville-laRue (Seine-Maritime), situé à l'extrémité ouest de la forêt. Même si, à la différence des autres sites fortifiés de cette famille, celui du Landin ne présente aucune trace de vestige 
maçonné en surface, sa topographie révèle néanmoins la présence d'un puissant fossé, qui verrouille totalement l'éperon.

Le groupe typologique des fortifications du XII ${ }^{\mathrm{e}}$ s. liées directement aux Beaumont-Meulan sera prochainement enrichi (2006-2008) par l'étude des sites de Beaumont-le-Roger, Goupillières, Gouttières, Brionne, Montfort-sur-Risle, Pont-Audemer et du Neubourg (Eure).

(Relevé et présentation Gilles Deshayes, Sébastien Lefèvre, Jimmy Mouchard).

\section{MESNIL-JOURDAIN (Eure)}

« Motte du manoir de Hellenvilliers »

La motte du Mesnil-Jourdain correspond aux critères les plus typiques de la fortification de terre. Toutefois, elle possède aujourd'hui un faciès très dégradé. L'étude microtopographique du site a permis d'en saisir les caractéristiques générales. Initialement, le tertre, en position de refuge au nord de l'espace castral, possédait une forme circulaire d'un diamètre approximatif de $22 \mathrm{~m}$. Il était sans doute complètement ceint d'un fossé et peut-être ponctuellement doublé d'un talus de contrescarpe au nord. L'enclos de la basse-cour, au sud du tertre, est fossilisé par un arc de bâtiments (des XV s. et $\mathrm{XVI}^{\mathrm{e}} \mathrm{s}$.) qui englobe l'église paroissiale. La vocation militaire de ces bâtiments est illustrée par la présence de fentes de tir, d'une canonnière et de trois consoles de mâchicoulis conservées en place. Le site, bien que modeste, a été l'objet d'une occupation continue à partir de la fin du XII ${ }^{\mathrm{e}}$. jusqu'à nos jours. Les modules observés (diamètre et forme du tertre, forme du fossé, emboîtement des différents éléments castraux, etc.) sont communs à d'autres sites normands, cependant, la motte du Mesnil-Jourdain reste originale car elle est le cœur d'un espace résidentiel pérenne et fixe autour d'elle un habitat villageois. La microtopographie permet en outre d'observer la place réservée au tertre primitif et les modifications qu'il a subies quand l'enclos castral a évolué vers une fonction de plus en plus résidentielle.

(Relevé et présentation sous la direction de Thomas Guérin).

FLAMBARD-HÉRICHER Anne-Marie

\section{ANNEXES}


Fig. $\mathrm{n}^{\circ} 1$ : Relevé de la fortification du « Bois de Dangu »

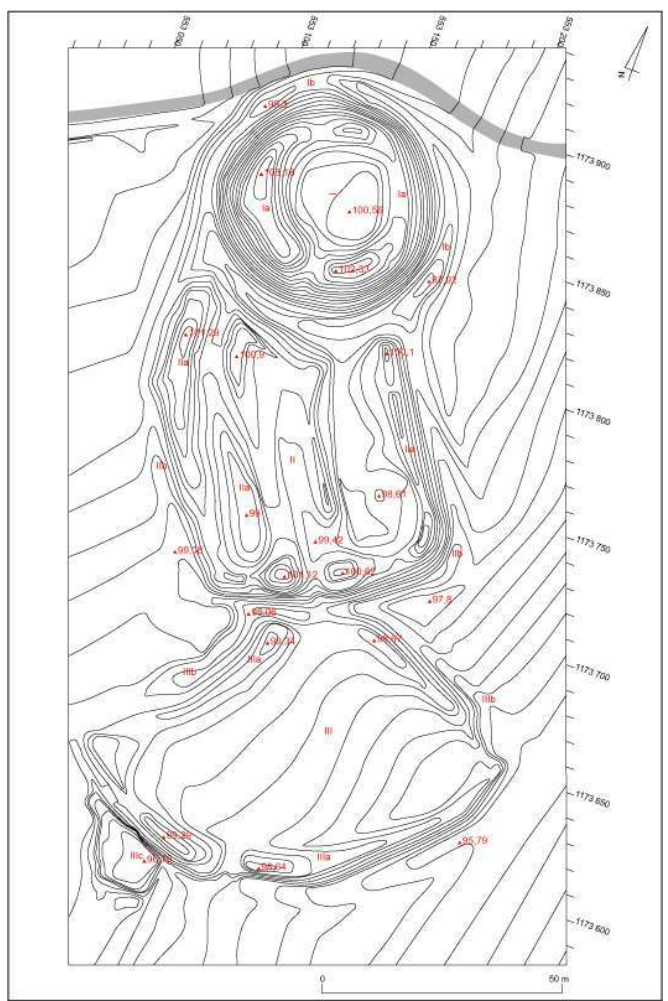

Auteur(s) : Lepeuple, Bruno (SUP). Crédits : Bruno Lepeuple (2005)

\section{INDEX}

Index chronologique : ép. contemporaine, Moyen Âge*, Temps Modernes

Thèmes : agger, architecture de terre, architecture militaire, barrage, basse-cour, bâtiment agricole, carte archéologique, château, cimetière paroissial, citadelle, courtine, dalle, défense, église, enceinte, enclos circulaire, enclos quadrangulaire, éperon barré, essartage, étude intrasite, féodalité, flore, fortification, fossé, galet, habitat fortifié, habitat groupé, hydrologie, marais, motte, parcellaire, peuplement, relief, sources écrites, taille, technique de construction, terrasse, topographie, village, zone humide Index géographique : Haute-Normandie operation Projet collectif de recherche (PCR)

\section{AUTEURS}

\section{ANNE-MARIE FLAMBARD-HÉRICHER}

SUP 